there are few published data to support these claims. In a prospective randomised trial in 140 patients that compared laparoscopic and open appendicectomy Tate et al found no significant differences between the groups in pain score, analgesic requirement, hospital stay, or time to return to work. ${ }^{2}$ The only significant finding was that the operating time was nearly twice as long in the laparoscopic group. In addition, conversion to an open operation was necessary in a fifth of the patients undergoing laparoscopy.

Further prospective randomised trials are needed to establish the place of laparoscopic surgery. Without such data the current enthusiasm for laparoscopic surgery may be unfounded.

S J MILROY A C QUINN WJ JAWCETT

\section{Department of Anaesthesia,}

St George's Hospital,

1 Monson JRT. Advanced techniques in abdominal surgery. BMF 1993;307:1346-50. (20 November.)

Tate JT, Dawson JW, Chung SCS, Lau WY, Li AKC. Laparoscopic versus open appendicectomy: prospective randomised trial. Lancet 1993;342:633-7.

\section{Management of asthma in general practice}

\section{Question patients about occupation and hobbies}

EDITOR,-Duncan Keeley correctly addressed the issues concerning treatment of asthma in genera practice once the condition has been diagnosed, including the questions to ask during routine consultations to gauge the severity of the disease. ${ }^{1}$ However, general practitioners need to ask all asthmatic patients one important question before consigning them to lifelong treatment: What are your occupation and leisure interests? Over 200 agents have been proved to cause occupational asthma, ranging from high molecular weight proteins such as bakers' flour, animal fur, fish proteins, and detergent enzymes to low molecular weight isocyanates and glutaraldehyde.

Initially patients with occupational asthma do not associate symptoms directly with work, but they wake at night coughing after exposure. Once they have become sensitised they produce specific IgE or IgG antibodies, which cause a more immediate response. During the next long term phase the difference in symptoms at home and work is not obvious. At this stage an absence of symptoms on holidays may be the only clinical clue. Smoking and atopy are variable risk factors depending on the causal agent.

The "single" allergen causing occupational asthma is a fascinating model for natural asthma. Prompt removal from exposure is likely to cure the asthma. Delay in removal and continued antigenic challenge results in cross sensitisation to other household allergens and chronic asthma. The implications for children initially allergic to one type of pet animal are obvious.

Serial peak flow measurements are the best method of diagnosis ${ }^{2}$ but require careful interpretation. Results can become confused by treatment with $ß$ agonists or inhaled steroids.

Herein lies the great opportunity for general practitioners to "cure" a chronic condition that has substantial costs for individual patients and the NHS. New causes and old examples of occupational asthma are always present in general practice.

The final diagnosis of occupational asthma requires specialist help from an occupational physician or chest physician but general practitioners have an important role in the diagnostic chain. They are best equipped to suspect the diagnosis because they know the patient, his or her family, and local industries.

JDM DOUGLAS

Tweeddale Medical Practice,

Fort William,

Inverness-shire $\mathrm{PH} 33$ 6EU

1 Keeley D. How to achieve better outcome in treatment of asthma in general practice. $B M F$ 1993;307:1261-3. (13 November.)

Burge PS. Problems in the diagnosis of occupational asthma. $\mathrm{Br} f$ Dis Chest 1987;81:105-15.

\section{Difficulty with spacer devices}

EDIToR,-Duncan Keeley provides a commonsense and comprehensive approach to the problems of managing asthma in general practice. ${ }^{1} \mathrm{He}$ makes the mistake, however, of extrapolating the advantages of spacer devices to elderly people, claiming that such devices are "easily used by . . elderly patients (except those with weak or arthritic hands)."

Though clinical experience might support this view, there has been controlled evaluation of inhaler technique with large volume spacers in elderly patients. Newman et al studied nine patients with a wide age range, only two of whom were over 70, and confirmed increased lung deposition with a single actuation in all patients including the elderly patients. ${ }^{2}$ Chu et al studied 53 patients aged 65 to 88 using metered dose inhalers and Nebuhalers. Although the patients found the Nebuhaler more convenient, there was no difference in percentage reversibility with the Nebuhaler. ${ }^{3}$ The patients' technique was not assessed.

In my clinical experience, most very elderly people find large volume spacers easy to use.

Many, however, experience difficulty in inserting the metered dose inhaler into the spacer, and others have an uncorrectable tendency to actuate the inhaler repeatedly before inhalation. A controlled study of elderly patients' technique is under way in my department.

Department of Geriatric Medicine,

MJ CONNOLLY

University of Manchester,

Barnes Hospital,

Cheadle,

Cheshire SK8 2NY

1 Keeley $\mathrm{D}$. How to achieve better outcome in treatment of asthma in general practice. $B M f$ 1993;307:1261-3. (13 November.)

2 Newman SP, Millar AB, Lennard-Jones TR, Moren F, Clarke SW. Improvement of pressurised aerosol deposition with Nebuhaler spacer device. Thorax 1984;39:935-41.

3 Chu WM, Lee YC, Dai LK, Ng NS, Tam HC, Ng YY. Comparison of Nebuhaler and conventional metered-dose inhaler in elderly patients. Curr Ther Res 1989;46:735-8.

\section{Neuroleptic malignant syndrome}

\section{May be caused by other drugs ... .}

EdrToR,-M F Bristow and D Kohen state that the neuroleptic malignant syndrome may occur in response to the sudden cessation of dopamine agonists as well as in patients treated with neuroleptic drugs. ${ }^{1}$ But the syndrome has also been reported after the administration of non-neuroleptic drugs, including lithium, metoclopramide, carbamazepine, antidepressants (including dothiepin and amoxapine), tetrabenazine, and metirosine. ${ }^{2-4}$

The authors emphasise that the pathogenesis of the syndrome is unknown and mention several possible central mechanisms. Although dopaminergic hypofunction in the basal ganglia seems the most likely cause of the rigidity and tremor, peripheral mechanisms may give rise to the other features. Sustained rigidity and tremor are likely to produce considerable heat as a result of muscle metabolism, and this could account for the fever. Fever and metabolic changes secondary to rhabdomyolysis could contribute to autonomic dysfunction and clouding of consciousness, the two remaining key features of the syndrome. The beneficial effect of dantrolene, a skeletal muscle relaxant, in reducing the duration of the syndrome ${ }^{5}$ supports the importance of muscular mechanisms in pathogenesis. Central abnormalities may also play a part-in particular, decreased activity in dopaminergic pathways in the hypothalamus may lead to fever.

Awareness of the epidemiology of the neuroleptic malignant syndrome may help alert clinicians to early cases. The male to female ratio among patients is $2: 1$, and $45 \%$ of patients are aged between 20 and 39, although the condition occurs at all ages. ${ }^{2}$ Ninety per cent of cases begin within 10 days of the start of treatment with a neuroleptic drug, though not necessarily for the first time, and a rapid increase in the dose during this period is usual. Although all neuroleptic drugs have been implicated, half of all reports have concerned haloperidol. 5

Department of Psychiatry,

Manchester Royal Infirmary,

Manchester M13 9BX

1 Bristow MF, Kohen D. How "malignant" is the neuroleptic

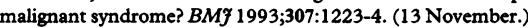
Kellam AMP. The (frequently) neuroleptic (potentially) malignant syndrome. Br f Psychiatry 1990;157:169-73.

3 Burke RE, Fahn S, Mayeux R, Weinberg H, Louis K, Willner $\mathrm{JH}$. Neuroleptic malignant syndrome caused by dopamine depleting drugs in a patient with Huntington disease. Neurolog 1981;31:1022-6.

4 Grant R. Neuroleptic malignant syndrome. BMF 1984;i:1690.

5 Shalev A, Munitz H. The neuroleptic malignant syndrome: agent and host interaction. Acta Psychiatr Scand 1986;73:337-47.

\section{... and other diseases}

EDrToR,-M F Bristow and D Kohen acknowledge that psychiatry is not the sole domain of the neuroleptic malignant syndrome. ${ }^{1}$ The syndrome has been described in patients with advanced cancer $^{2}$ and AIDS. $^{3}$ Malnutrition and severe debility may be precipitating factors in susceptible patients. Outside psychiatry the diagnosis may often be missed as three of the four standard diagnostic criteria (fever, autonomic instability, and altered consciousness) may be seen as evidence of advancing malignant or other disease. All of these factors will contribute to an underestimation of its true incidence.

WILIIAM M O'NEILI

Bristol Oncology Centre,

Bristol BS2 8ED

1 Bristow MF, Kohen D. How "malignant" is the neuroleptic malignant syndrome? BMf 1993;307:1223-4. (13 November.) 2 O'Neill WM. The neuroleptic malignant syndrome. Clinical Oncology 1992;2:241-2.

3 Breitbart W, Marotta RF, Call P. AIDS and neuroleptic malignant syndrome. Lancet 1988;332:1488-9.

\section{Don't confuse with anticholinergic intoxication}

EDrTor,-In their editorial on the neuroleptic malignant syndrome M F Bristow and D Kohen refer to the four main signs (fever, rigidity, autonomic instability, and altered consciousness), noting that incomplete varieties are encountered. In their brief discussion of the differential diagnosis, however, they do not mention the clinical resemblance between this condition and anticholinergic intoxication.

Anticholinergic intoxication causes fever, autonomic instability, and altered consciousness and is likely to occur in patients with rigidity induced by neuroleptics. ${ }^{2}$ Patients with severe psychiatric illness are not uncommonly treated with escalating doses of one or more neuroleptic drugs with anticholinergic properties. Moreover, such 